Supplement of Atmos. Chem. Phys., 21, 13051-13065, 2021

https://doi.org/10.5194/acp-21-13051-2021-supplement

(c) Author(s) 2021. CC BY 4.0 License.

(c) (1)

Atmospheric

Chemistry

and Physics

Supplement of

\title{
Urban aerosol chemistry at a land-water transition site during summer - Part 1: Impact of agricultural and industrial ammonia emissions
}

Nicholas Balasus et al.

Correspondence to: Christopher J. Hennigan (hennigan@umbc.edu)

The copyright of individual parts of the supplement might differ from the article licence. 


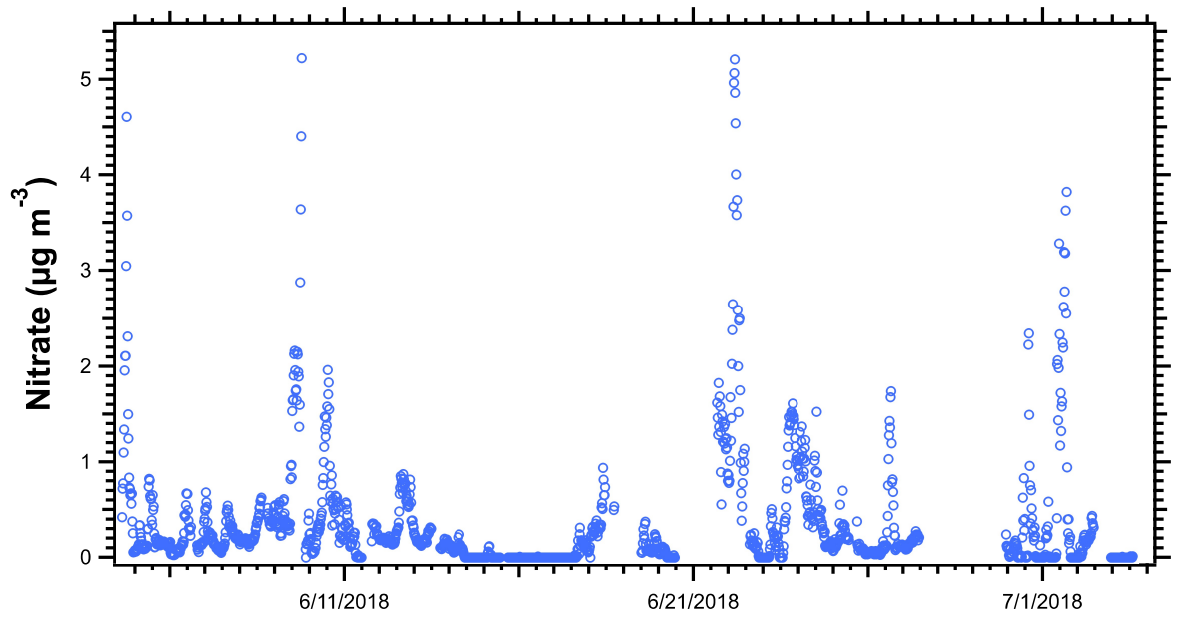

Figure S1. Time series of aerosol $\mathrm{NO}_{3}^{-}$for the duration of the OWLETS-2 campaign. 

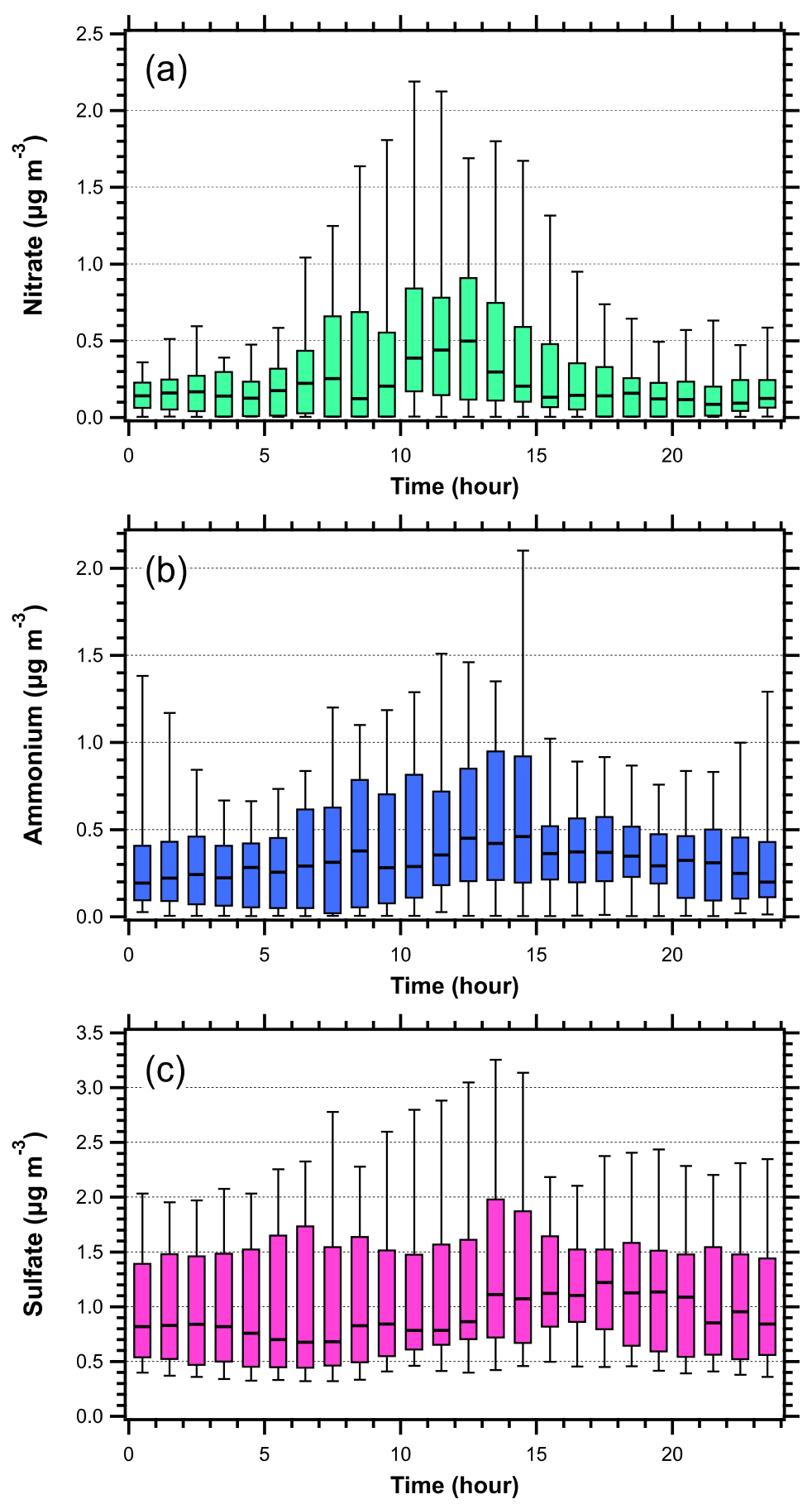

Figure S2. Diurnal profile of aerosol nitrate, ammonium, and sulfate on local time (EDT). The $10^{\text {th }}, 25^{\text {th }}, 50^{\text {th }}, 75^{\text {th }}$, and $90^{\text {th }}$ percentiles are marked. 


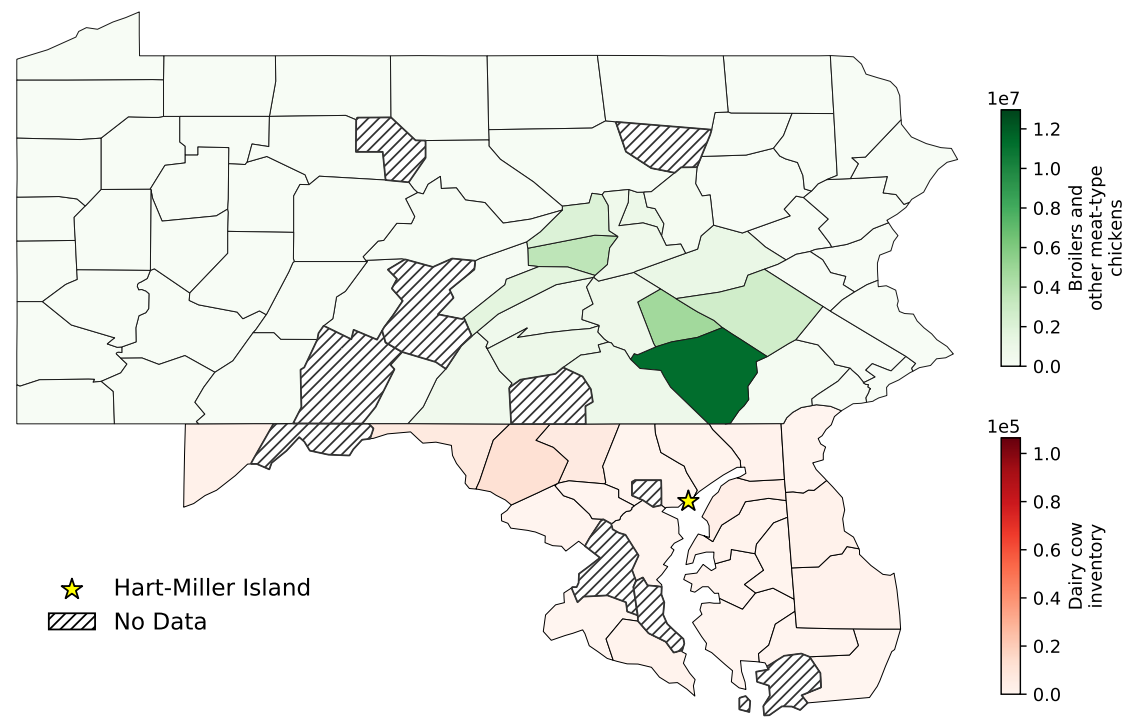

Figure S3. Inventories of dairy cows in Maryland and Delaware and broiler and other meat-type chickens in Pennsylvania. Data are from the 2017 Census of Agriculture (USDA, 2017). 


\section{References}

USDA: Census of Agriculture, Volume 1, Chapter 2: County Level Data, Tech. rep., 2017. 